\title{
When Universal Access does not go to plan: Lessons to be learned
}

\author{
Simeon Keates ${ }^{1}$ \\ ${ }^{1}$ University of Greenwich, Medway Campus, Chatham Maritime, ME4 4TB, United Kingdom \\ ${ }^{1}$ s. keates@gre.ac.uk
}

\begin{abstract}
While the theory of designing for Universal Access is increasingly understood, there remain persistent issues over realising products and systems that meet the goal of being accessible and usable by the broadest possible set of users. Clearly products or service that are designed without even considering the needs of the wider user base are implicitly going to struggle to be universally accessible. However, even products that have been designed knowing that they are to be used by broad user bases frequently still struggle to achieve the ambition of being universally accessible. This paper examines a number of such products that did not achieve, at least initially, the desired level of universal accessibility. Principal recommendations from each case study are presented to provide a guide to common issues to be avoided.
\end{abstract}

Keywords: Universal Access, robots, kiosks, digital television, HCI, input systems.

\section{$1 \quad$ Introduction}

The need for universal access (UA) is well established across the globe [1] and is reinforced through legislation in many countries [2].

The theoretical basis for achieving universally accessible products is becoming well established and mature [3]. Most approaches to UA are derived from earlier work in the field of usability by such notable authors as Nielsen [4], Shneiderman [5] and Norman [6]. Their work, in turn, followed that from research centres such as Xerox PARC [7].

Early usability texts focused almost exclusively on able-bodied users and attention to users with functional impairments was comparatively rare. However, as usability methods matured, they began to extend to include accessibility issues that had, up to this point, been considered to be a separate design domain [8]. Different approaches were developed at this time, with different names, such as Universal Design (typically in the US and Japan) [e.g. 9], Inclusive Design (typically in Europe) [e.g. 10] and Design for All (also Europe) [e.g. 11] and these came from different geographical regions, cultures and application areas, such as buildings access, IT equipment or government services. However, all these approaches had a number of common features, including: 
- understanding the user wants, needs and aspirations [8], i.e. what they basically want to accomplish (note - these need not be task-driven, but can be focused on experiences or sensations, for example);

- understanding the context of use, i.e. when and where it is to be accomplished; and,

- involving users in the design process, e.g. through participatory design or critical user forums [12].

Second generation methods, such as Countering Design Exclusion (CDE) and usersensitive design [13] add to or augment these methods, for example:

- understanding where problems lie with existing designs, so that designers can focus on areas with known issues or deficiencies in terms of accessibility and usability (CDE) [8];

- using actors or other representatives/representations of the users to help designers where users may not be available for participatory design (pioneered by the team that developed user-sensitive design) [13]; or,

- using simulations to provide greater understanding (what can be thought of as simulation-assisted design) [14].

However, while there is a substantial and still-growing body of work of how such design ought to be undertaken to achieve an effective Universal Access solution, the reality is that many products are still far from universally accessible [15]. This paper explores examples that were intended to be usable and accessible by the widest possible user base, but failed to do achieve their goal. The examples will cover many areas of functional impairments, whether motor function, vision, hearing or cognitive, and areas of life endeavour [16] rather than focusing solely on computer access. However, the first examples will come from that field.

\section{Novel computer access systems}

It has long been known that the typical keyboard and mouse arrangement for computer access is innately problematic for those with moderate to severe functional impairments, whether motor impairments or poor vision [17]. Substantial research resources have been applied to the issues, with solutions ranging from very low-tech solutions, such as keyguards and large keyboards, to very high-tech ones such as speech recognition and advanced word prediction. Improved computer processor power and many years of development of the underlying models and algorithms have improved the reliability of such sources of inputs immeasurably. However, the keyboard and mouse still dominate human-computer interaction [18]. It is interesting to explore why, even with the advent of near ubiquitous devices that lack keyboards, such as smart phones and tablets.

An example of why these other technologies rarely manage to displace the keyboard and mouse can be found in the development of Jester, a prototype gesture recognition system developed some time ago [19]. The results from that system are as valid today as they were then. 
Users typically consider how well a system performs on three criteria when assessing whether it meets their needs or not:

- Efficiency, i.e. the time taken and effort expended to complete a task;

- Effectiveness, i.e. the ability to complete the task;

- Satisfaction, i.e. user contentedness with the interaction.

Methods for calculating these measures have been formally proposed by the International Standards Organization [20]. Many system designers, though, rarely consider all three of these attributes when evaluating their designs. For example, those developing new computer input systems often focus only on the recognition rate of the software, i.e. what proportion of the input is recognized correctly by the system. However, while the recognition rate is clearly very important, it represents only one contributing element to the three metrics described above, meaning that other elements are being disregarded.

Jester was developed as a means of enabling users with moderate to severe motor impairment to interact with a computer via head and/or hand gestures [21]. Initial results showed that gesture recognition rates of over $90 \%$ could be obtained with practice and a small vocabulary of input gestures (left, right, up, down, yes/nod and no/shake) [19]. Much research at the time would have stopped at that point to report the results in the hope that a means of commercialization would be found at that point. The research team did not stop there, though. Fig. 1 shows Jester being used with both head and hand input.

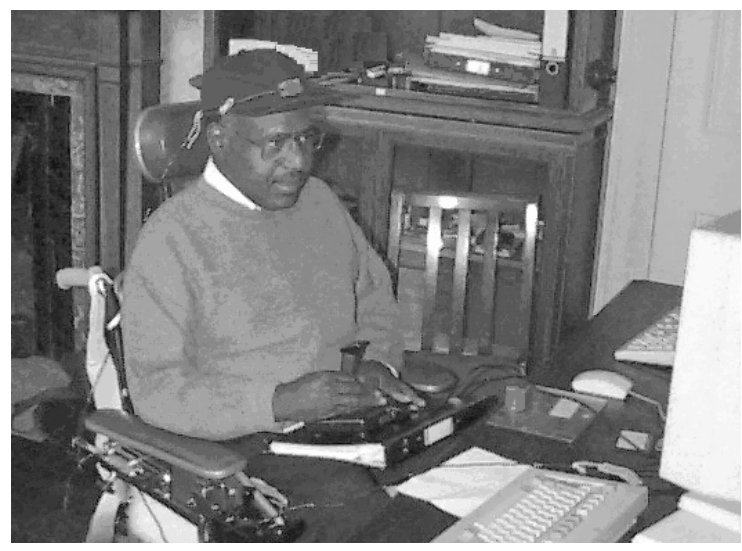

Fig.1. Jester in use. Note the plastic cube mounted on the baseball cap for head gestures and the analogue joystick for hand gesture. Both could be used independently or combined.

When Jester was tested by a hospital-based occupational therapy service [22], they appreciated the novelty of the input, but reported that the users were not sufficiently impressed to consider replacing their existing input systems, such as binary switches, with the new system even though it appeared to offer more freedom and flexibility. 
Further investigation revealed that while the recognition rate was considered satisfactory, the effort required to produce controlled gestures that Jester could recognize was considerable. Additionally, the time taken to produce and recognize the gestures meant that the throughput, i.e. the rate of useful information transfer between the user and the computer, was lower than for a simple binary switch that took minimal effort to control, was very configurable to a user's personal needs and required very little training to master [23]. The cost of the Jester system was also considered prohibitive.

Attempts to improve the throughput by increasing the usable input gesture vocabulary by combining head and hands gestures proved counter-productive. The cognitive and physical demands placed upon the users were increased significantly to the point where the interaction rate and throughput actually decreased [18]. Gesture recognition is now largely the province of stylus input rather than head and hand movements. The most notable exceptions are to be found in gaming systems, such as the Nintendo Wii and Microsoft Kinect.

There are three key conclusions that can be drawn from the Jester prototype for outcomes that are to be avoided:

1. Do not develop solutions that are too expensive, especially where cheaper options are available.

2. Do not develop solutions that fail to consider all elements of the interaction or focus only on one element of it.

3. Do not develop solutions that place too many demands (whether physical, sensory or cognitive) on the user.

\section{Improving the effectiveness of existing input systems}

Sometimes novel solutions for enabling universal access to computer systems can be found from products designed for other uses. One such example was the Logitech Wingman Force Feedback Mouse [24] - henceforth referred to as the Wingman mouse (see Fig. 2). This mouse was developed to enrich gaming experiences by supporting haptic force feedback through the use of a toolkit developed by Immersion. The toolkit enabled the mouse to emulate the feeling of moving over a tactile landscape where the edges of windows could be felt by a small judder of the mouse, for example. Gravity effects could also be added to on-screen elements, actively pulling the cursor into the elements [25].

While such effects can be achieved using solely visual feedback whereby the cursor moves on its own, users typically find such assistance somewhat disorienting as it breaks the relationship between what their eyes see (the cursor location on screen) and their hands/arms feel (the position of the mouse under their hand). The Wingman mouse solved this issue by actually moving the mouse autonomously. The mouse had a metal pin under it that was connected to three motors via three cables arranged $120^{\circ}$ apart. The mouse was capable of exerting directional forces of up to 10 Newtons.

User trials were conducted with a range of users with severe motor impairments arising from conditions such as cerebral palsy and muscular dystrophy. Using the Wingman mouse in conjunction with on-screen haptic gravity wells improved the 
average throughput across all the motor-impaired users to something broadly comparable with able-bodied users using an unmodified mouse [23]. Given the level of impairment of the users, this was an astonishing result and offered great potential for improving computer access for many users.

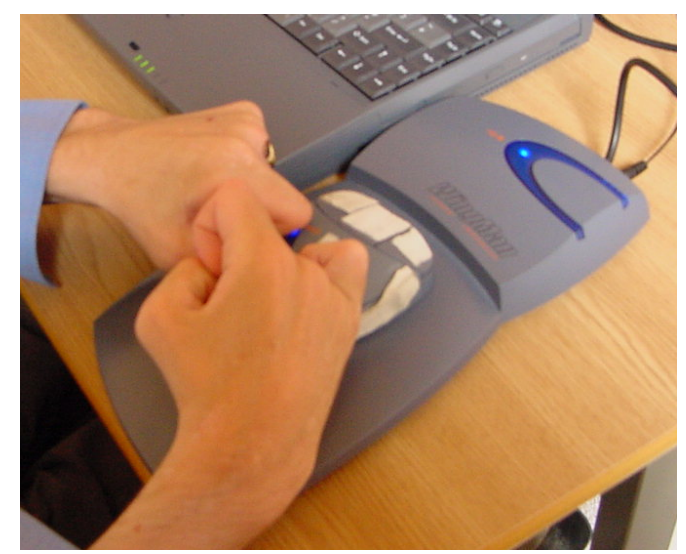

Fig. 2. The Wingman Force Feedback mouse being used by a user with cerebral palsy. Note the user's curled fingers and the hockey tape added to the buttons to stop the user's fingers slipping off them.

However, Logitech then withdrew the mouse and replaced it with one that had a small oscillator inside it, which could only simulate vibratory output and not move the mouse autonomously. This was extremely unfortunate for those users who stood to benefit from the technology. Informal enquiries found that the reason the mouse was withdrawn was probably connected to a legal case in the US where the parents of a child who had allegedly developed repetitive strain injury from playing on a Sega Rumblepad for several hours a day. Since the forces generated by the Wingman mouse were substantially greater than the Rumblepad, Logitech apparently withdrew the product and replaced it with a re-engineered one as a precautionary measure against possible litigation. The conclusion to be drawn from this example is:

4. Do not develop solutions without considering the risks that may be presented to the users.

\section{$4 \quad$ Introducing new interaction paradigms}

Looking further afield than computer access, other systems rely upon softwaremediated interaction, such as kiosks, information points and smart televisions. One research study into the design of digital set-top boxes undertaken just prior to the switchover of from analogue to digital television provision in the UK highlights some of the issues that can arise where development focuses on the hardware and not on the software. 
Prior to the digital switchover, televisions were capable of receiving the analogue signals from an external aerial and could be controlled by a straightforward infrared remote control. After digital switchover, viewers would either have to purchase a new integrated television that could receive and process the digital signals or else purchase a separate set-top box that would change the digital signals into analogue ones that the older televisions could display. Using a set-top box would necessitate the use of a second remote control.

The UK Department of Trade and Industry was concerned that switching off analogue TV signals would lead to some viewers being unable to watch the new digitalonly services [26]. They commissioned a company, Scientific Generics, to investigate how many people may potentially have been excluded by the digital switchover. The initial approach to the challenge was to recruit users with significant functional impairments, such as deafness and blindness, to use a range of the new set-top boxes. However, after discussions with specialists in inclusive design, the aim was adjusted to identify users at the boundary of being able to use the new boxes. The idea was that if you could identify those who could just use the system, anyone with more severe functional impairments would most likely be unable to use it [27].

A number of older adults were recruited with a range of minor to moderate functional impairments (see Fig. 3), along with a number of younger users with more severe impairments. The results showed that while there were a number of physical access issues, the biggest causes of exclusion were cognitive in origin. Examples of the confusion were around the use of both remote controls, i.e. the one for the television and the one for the set-top box. To keep costs down, the set-top box designers used cheap generic remote controls that were not designed specifically for the boxes, but could be used to also control VCRs, DVD players and televisions. As a consequence, both remote controls often looked to offer the same functions, but one operated some of them and the other operated the rest of them. The users often got confused over which did which. Newer designs for such boxes are now tailored specifically to set-top box operations.

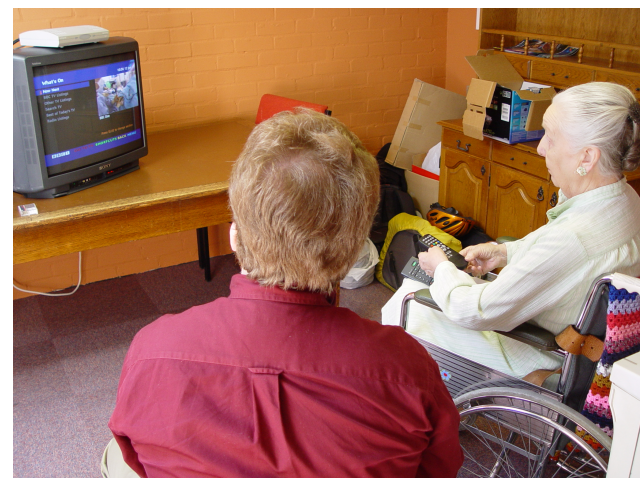

Fig. 3. The digital set-top box user trials. Note the pale grey box on top of the television set and the multiple remote controls on the user's lap. 
Another area of exclusion was the software interface itself. As part of the user evaluation protocols, users were asked to complete a range of tasks including finding the local weather using the in-built teletext service used in the UK. The analogue teletext pages were structured around a page numbering system that allowed users to navigate either by typing in a three digit page number directly or using four colourcoded "fastext" buttons to jump to common page choices. On Ceefax, the BBC's teletext service, page 100 (the first page) is an index page and each of the " 00 " pages was the index page for that subsection. For example, pages 100-199 were usually for news, pages 200-299 were for finance, 300-399 were sport, etc. Viewers typically learned the page numbers for their preferred pages, such as page 400 for the weather subsection, or else used the fastext buttons to follow the recommended links to get there.

On the digital television service, the inherent search space was no longer so obviously analogous to navigating a book with sections and subsections. There were no page numbers displayed on the screen and viewers could only navigate using prompts or the cursor keys on the remote control. The mental model used for the navigation was based on web pages, which do not typically use a page numbering system and support much more flexible navigation. This new approach made sense to the designers, who were clearly web-savvy computer users.

However, the older adults in the user session became very confused where they were in the digital teletext service, because this was a completely new way of navigating information and had no signposting to indicate where they were or how they had got there, unlike the old page number system. Following the results of this investigation, page numbers were reintroduced and the older adults found the new design far more usable. It is as important to consider cognitive aspects of interaction as it is to look at the physical ones [28].

The conclusion from this experience is:

5. Do not use inappropriate interaction paradigms.

6. Take time to understand the users - their background, knowledge and experience.

\section{$5 \quad$ Robotic universal access assistants}

As discussed earlier, in the early stages of the development of any new and innovative product, the focus is principally on developing the new technology, especially overcoming the inherent engineering challenges to make something that accomplishes the basic task set required [29]. Users typically get overlooked in this early stage of development, not least because if the engineering challenges are significant, there is no guarantee that a feasible product may ever be developed [30]. Instead, designers typically end up designing something that they themselves, regarding themselves as suitable substitutes for the actual end-users [31]. Consequently, the almost inevitable outcome is a product that works best for users who are most like the designer, including attributes such as their knowledge (both background knowledge and detailed knowledge of the product), experiences, capabilities, anthropometrics, and so on [32]. Those who are notably different, which those who would benefit most from a univer- 
sal access-based approach usually are, do not fare so well. All of these challenges are difficult enough where the hardware platform is widely understood, such as in humancomputer interaction. However, when developing systems that involve new hardware, the challenges faced increase.

For example, in the 1990s, the European Union funded a number of research programmes through its TIDE (Telematics for the Integration of Disabled and Elderly people) initiative to develop robotic assistants for users with severe functional impairments. Over $\$ 150 \mathrm{~m}$ was invested, supporting the development of solutions from office workstations to wheelchair-mounted robots [33]. However, the success of those robots and others developed under similar initiatives was far from satisfactory [34]. Only the Handy 1 robot arm [35] and MANUS wheelchair-mounted robot [36] achieved any degree of successful take-up. Fewer than ten of each of the other robots investigated were produced [34].

Looking at the two more successful robots, the Handy 1 was created by a small British start-up company with a view to being launched as a commercial product. It consisted of a generic robot arm mounted on a mobile base, allowing the design team to focus on the task and the user interaction rather than the development of a brand new robot arm. Attached to the arm was a simple spoon. The users' food was placed in 5 segregated sections of a tray and, through a straightforward interface, the users could feed themselves. This robot allowed many users to feed themselves independently for the first time in their lives. Thus a real need had been identified and a reasonably cheap solution (c. \$6000) developed. A second variant was introduced allowing users to apply make-up. Approximately 150 units had been sold by 1997 [34].

The MANUS robot was developed in the Netherlands and it was fundamentally a robot arm mounted on the side of a wheelchair. As such, the robot was inherently mobile, albeit with the disadvantage of making the wheelchair notably wider in certain configurations. The cost was significantly more than the Handy $1(\$ 35,000)$, but sales were helped by a pre-existing agreement between the development team and the Netherlands government, which was the largest buyer.

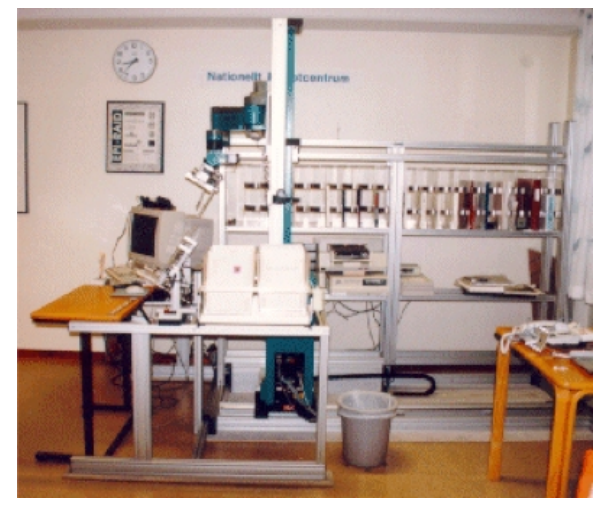

Fig.4. The EPI-RAID office workstation consisting of an RTX robot arm mounted on a gantry in a purpose-built office. 
The typical causes of failure in the other robots were illustrated by the EPI-RAID workstation [30] (see Fig. 4). This robot was developed to help a user with severe motor impairments to move documents and books around an adapted office space. Like the Handy 1, it used a generic robot arm, but the arm was mounted on a gantry so it could move around the office space to pick papers and files from shelving and place them on a page-turning device for the user to read. Unlike the Handy 1, where the user sat close to the robot arm so the range of movement required was limited, the EPI-RAID system needed to controllable at a greater distance, with a larger range of possible movement and needed greater accuracy. It also needed to support a wider variety of interactions as a direct consequence of the broader range of functional tasks that it was designed to support.

The focus on meeting the technical challenges of the robot, the gantry and the grippers meant that the user interface was not addressed until quite late in the design process. Furthermore, the complexity of the engineering challenges pushed the cost of the overall system up to at least an order of magnitude more than the Handy 1 . User trials showed that the technical challenges of the robot had been met, but the user interface was too rudimentary to be useful. To improve it would have required substantial redevelopment, with the commensurate costs that would have pushed the price of the system up even further. The final nail in the coffin was that EPI-RAID was overtaken by other developments in technology. The emerging ready availability of CD-ROMs and the Internet shortly after the commencement of the project made information available on the computer directly without needing to manipulate hard copies, making the concept behind EPI-RAID somewhat redundant.

The other TIDE funded projects suffered from very similar issues, i.e. cost of the system, the time to develop them being too long, being superseded by new technologies and generally too little focus on the user interface, especially its usability and accessibility. The general conclusions to draw from these projects are:

7. Do not focus on the development of the technology to the exclusion of consideration of the user.

8. Develop solutions that meet genuine needs, wants and aspirations of the users.

9. Allow enough development time to ensure the user interface is satisfactory.

\section{$6 \quad$ Access to information services}

Another set of projects that experienced similar issues to rehabilitation robotics come from almost a decade later and show that while the technology had changed, the underlying issues encountered largely had not.

The UK postal service, Royal Mail, was looking to make its post offices more high-tech and approached a number of suppliers to propose possible solutions to do so. Two solutions were put forward, the Personal Information Point [37] and the Your Guide kiosk [38]. Before these products were rolled out, Royal Mail commissioned user trials to establish whether they were sufficiently usable and accessible. Neither product was introduced following the identification of issues through those user trials. 


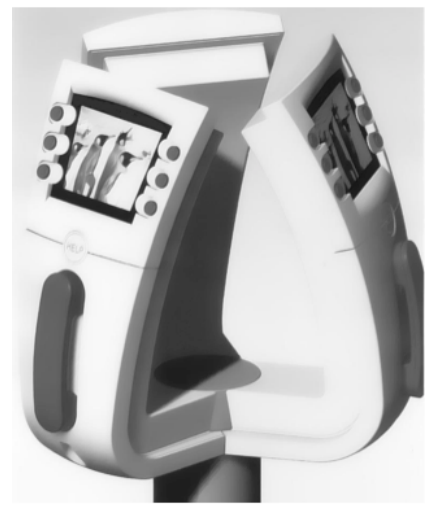

Fig. 5. The Personal Information Point. Note the telephone handset for audio output, the LCD screen for visual output and the 6 buttons arranged either side of the screen for input. To use the PIP, the user would have to be able to see the screen, hear the audio and simultaneously hold the handset and press the buttons.

The first solution, the Personal Information Point (PIP - see Fig. 5), had originally been developed for use in museums to help visitors navigate around the exhibits and also provide more detailed information on those exhibits. It comprised one to three "heads" mounted on a fixed column. Each head held a small LCD panel, approximately $12 \mathrm{~cm}$ across, three buttons arranged on both the left and right hand edges of the screen and a telephone handset. The content on the screen could either be static text or video and any auditory output was provided via the telephone handset. It was straightforward to see how the PIP could be used in a museum context with this design.

However, the proposal was to use this same design in busy and noisier post office environments to provide detailed information about National Savings investments products, such as savings accounts, investment bonds, etc. These products are governed by regulatory rules that require lots of small print to be shown and are intrinsically complex. This was anticipated to result in several screens-worth of information needing to be displayed for each product as well as the ability to compare across products.

The design team was all comparatively young, male, able-bodied and were not used to designing products of this type. The PIP represented something of a departure from their usual product ranges. The target users identified, though, were typical post office customers, with a particular focus on older ladies collecting their pensions. A pre-user trial analysis of the design was undertaken to evaluate where the issues might be expected when users attempted to interact with the PIP.

This pre-trial evaluation highlighted a broad range of issues. For example, the screen was positioned at such a height that while the young, male design team could see it, half the older, female users probably would not have done according to data from anthropometric standards. Similarly, the use of the telephone handset would have presented significant motor and hearing challenges from the requirement to hold 
the handset and listen to audio output in a fairly noisy environment. The small screen and requirement to display lots of text presented significant vision challenges as the text displayed would either have to be very small or else needed to be presented over multiple screens, which would then have posed memory and motor challenges instead. The use of the six buttons and their rather high location posed motor and dexterity problems with the users potentially needing to raise either arm to push them. The capability demands the would have been placed on the users were evaluated against the prevalence of capability data collected from the 1996/7 Disability FollowUp Survey [39] - a national survey of c. 8000 people to find out what capability limitations they experienced on a regular basis. An online tool had been developed at the University of Cambridge [40] and an updated version is also available [41].

The results of the pre-study analysis were very surprising. Approximately half of the target population was anticipated to experience significant difficulties using the PIP just from the screen being too high and a quarter of all adult women (not just those over the age of 65) were anticipated to not be able to see the screen. Combining the anthropometric exclusion with the anticipated capability demands resulted in up to $45 \%$ of the UK adult population being potentially excluded without even beginning to look at the cognitive demands from the information being displayed on the screen [38].

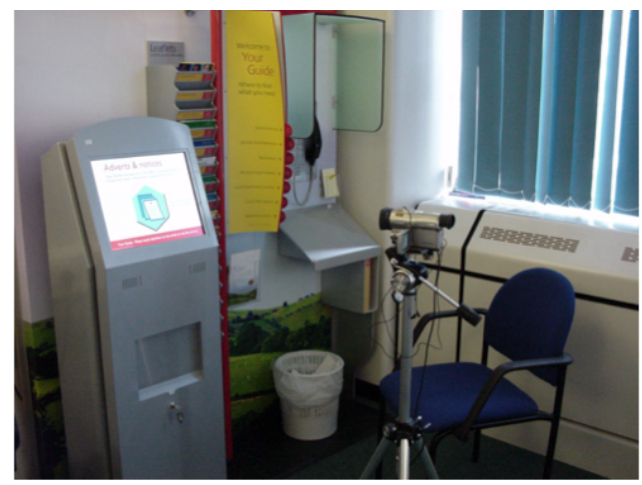

Fig. 6. The Your Guide kiosk, its surround and the free-phone telephone. Note the plastic shroud around the telephone and the black foam rubber that had to be added to stop taller people from hitting and hurting their heads.

Royal Mail did not proceed with the PIP and an alternative supplier proposed the Your Guide kiosk (see Fig. 6). This kiosk was much more traditional in design, comprising a large touchscreen positioned at a much lower height. Users could operate the kiosk while standing or seated. A separate "free-phone" telephone was provided adjacent to the kiosk. The kiosk was designed to provide access about the local town, including governmental and council services, utilities contacts, leisure facilities and the like. While the kiosk overall was physically much more accessible than the PIP, the users still could not access the information easily. As with the digital television example earlier, the principal challenges were around some of the design choices, 
such as the layout of the onscreen keyboard, and the use of icons that the users did not understand. The designers had chosen to use fairly common computer icons, but the users in the trial sessions were not regular computer users, so did not recognize or understand the more abstract icons.

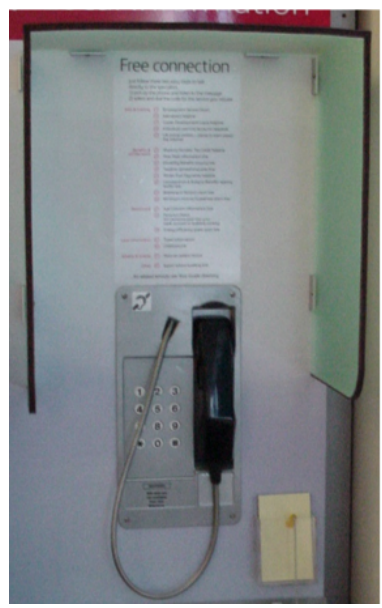

Fig. 7. The Your Guide telephone. Note the cable obscuring the sunken, rubberized buttons.

There were still a number of physical access issues, especially for the telephone (see Fig. 7). The telephone cable hung across the keypad, the keys were soft, rubberized ones that needed to be pushed inwards and bent under the user's fingers, and a privacy surround had been added, but was too low so anyone slightly above average height would bang their forehead on it.

The conclusions from both kiosks were:

10. Be mindful of anthropometric issues, especially where the users are very different to the designers.

11. Remember that designers and users are different.

12. Be careful about trying to adopt solutions that are applied outside of the primary use for which they were developed.

\section{Universal access throughout the interaction}

The final example is a fairly straightforward one. Even the best-designed products can be let down by a small, seemingly trivial detail possibly buried somewhere in the chain of interactions between a user and a product or service [42]. It is necessary to check all stages of the interaction to ensure all aspects are accessible.

For example, it is now possible to buy mobile phones (cell phones) with large keys for users with reduced vision and/or limited dexterity. One such example is shown in Fig. 8 . The buttons are fairly straightforward to see for everyone with reasonable eyesight. However, Fig. 8 also shows a page from the instruction manual, where the font 
is notably smaller. While this is probably not going to stop a user from being able to use the phone, it shows that the thinking process across all aspects of the design of the product, which includes packaging and instructions, was not as complete as it might be.

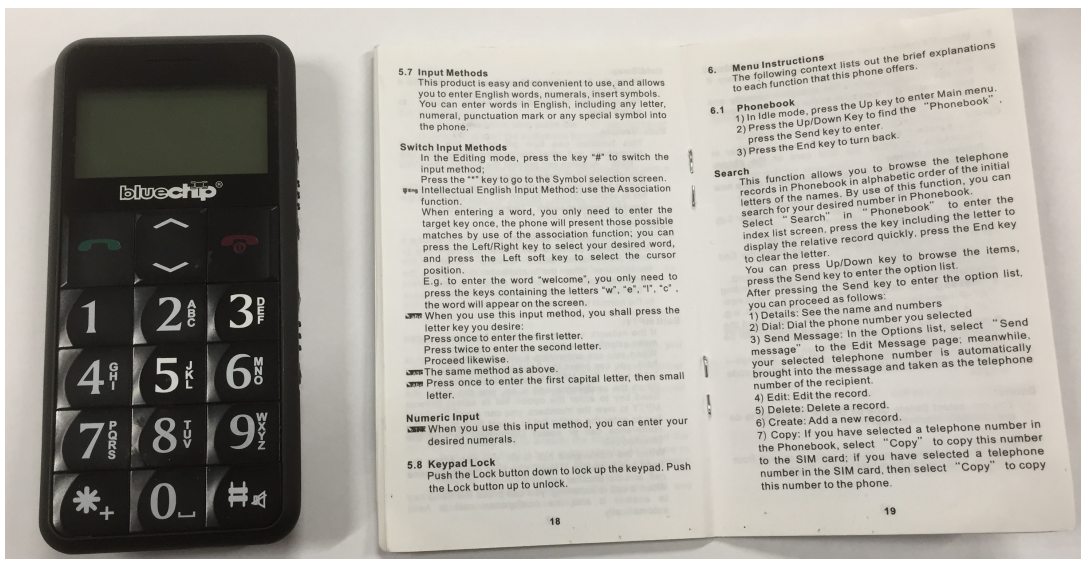

Fig. 8. The Big Button mobile phone and instruction manual. Note the disparity in size between the labels on the keypad and the size of font in the instructions.

The conclusion from this example is:

13. Remember to check all stages of the interaction process from set-up to decommissioning and ensure that they are all equally accessible.

\section{Summary}

This paper has examined a number of case studies where designers had striven to develop products to meet the needs of the widest possible sets of users, but had not quite achieved the outcomes desired. Each case study highlighted different issues that, taken together, make for a useful set of reminders for all designers:

1. Do not develop solutions that are too expensive, especially where cheaper options are available.

2. Do not develop solutions that fail to consider all elements of the interaction or focus only on one element of it.

3. Do not develop solutions that place too many demands (whether physical, sensory or cognitive) on the user.

4. Do not develop solutions without considering the risks that may be presented to the users.

5. Do not use inappropriate interaction paradigms.

6. Take time to understand the users - their background, knowledge and experience. 
7. Do not focus on the development of the technology to the exclusion of consideration of the user.

8. Develop solutions that meet genuine needs, wants and aspirations of the users.

9. Allow enough development time to ensure the user interface is satisfactory.

10. Be mindful of anthropometric issues, especially where the users are very different to the designers.

11. Remember that designers and users are different.

12. Be careful about trying to adopt solutions that are applied outside of the primary use for which they were developed.

13. Remember to check all stages of the interaction process from set-up to decommissioning and ensure that they are all equally accessible.

\section{References}

1. Stephanidis, C.: The Universal Access handbook. CRC Press: Boca Raton, FL (2009).

2. Keates, S.: Designing for Accessibility - A business guide to countering design exclusion. CRC Press: Mahwah, NJ (2007).

3. Clarkson, P.J., Coleman, R., Lebbon, C., Keates, S.: Inclusive Design - Design for the whole population. Springer-Verlag, London, UK (2003).

4. Nielsen, J.: Usability engineering. Morgan Kaufmann, San Francisco, CA (1994).

5. Shneiderman, B.: Designing the User Interface: Strategies for effective Human-Computer Interaction. Addison-Wesley Longman. Boston, MA, USA (1997).

6. Norman, D.: Affordance, conventions and design. Interactions, 6(3) (May 1999), 38-43 (1999).

7. Card, S., Moran, T.P.; Newell, A.: The Psychology of Human-Computer Interaction. Lawrence Erlbaum Associates, Mahwah, NJ (1983).

8. Keates, S., Clarkson, P.J.: Countering design exclusion - An introduction to inclusive design. Springer-Verlag, London, UK (2003).

9. Goldsmith, S.: Universal Design. Architectural Press, Routledge, UK (2000).

10. Keates, S., Clarkson, P.J., Harrison, L.A., Robinson, P.: Towards a practical inclusive design approach. Proceedings of ACM Conference on Universal Usability (CUU 2000), ACM Press, pp. 45-52 (2000). doi: 10.1145/355460.355471

11. Stephanidis, C.: Design for all. The Encyclopedia of Human-Computer Interaction, 2nd Ed. (Soegaard, M., Dam, R.F., editors), The Interaction Design Foundation (2013).

12. Dong, H., Clarkson, P.J., Cassim, J., Keates, S.: Critical user forums-an effective user research method for inclusive design. The Design Journal, Routledge, 8(2), $49-59$ (2005). doi: $10.2752 / 146069205789331628$

13. Newell, A.F., Gregor, P., Morgan, M., Pullin, G., Macaulay, C.: User-sensitive inclusive design. International Journal on Universal Access in the Information Society (UAIS), Springer, 10(3), 235-243 (2011). doi: 10.1007/s10209-010-0203-y

14. Cardoso, C., Clarkson, P.J.: Simulation in user-centred design: helping designers to empathise with atypical users. Journal of Engineering Design, 23(1), 1-22 (2012).

15. Dong, H., Keates, S., Clarkson, P.J., Cassim, J.: Implementing inclusive design: the discrepancy between theory and practice. Proceedings of the 2002 ERCIM Workshop on User Interfaces for All, Lecture Notes in Computer Science, vol. 2615, Springer, Berlin, pp. 106-117 (2002). doi:10.1007/3-540-36572-9_8

16. Keates, S., Kozloski, J., Varker, P.: Cognitive impairments, HCI and daily living. Proceedings of International Conference on Universal Access in Human-Computer Interaction. 
LNCS, Vol. 5614. Springer-Verlag: Heidelberg, pp. 366-374 (2009). doi: 10.1007/978-3642-02707-9_42

17. Trewin, S., Keates, S.: Computer access for motor impaired users. Encyclopedia of Human-Computer Interaction. IGI: London, UK, pp. $92-99$ (2006).

18. Trewin, S., Pain, H.: Keyboard and mouse errors due to motor disabilities. International Journal of Human-Computer Studies, 50(2), 109-144 (1999).

19. Keates, S., Robinson, P.: Gestures and multimodal input. Behaviour and Information Technology, Taylor and Francis Ltd. January-February, 18(1), 36-44 (1999). doi: $10.1080 / 014492999119237$

20. International Standard Organization (ISO): ISO 9241-11: ergonomic requirements for office work with visual display terminals (VDTs), Part 11: Guidance on Usability Specification and Measures. Technical report. ISO, Geneva (1998).

21. Keates, S., Perricos, C.: Gesture as a means of computer access. Communication Matters. 10(1) 17-19 (1996).

22. Keates S., Potter R., Perricos C., Robinson P.: Gesture recognition - Research and clinical perspectives. In: Proceedings of RESNA '97 (Pittsburgh, Pennsylvania), RESNA Press, pp. 333-335 (1997).

23. Keates, S.: Measuring acceptable input - What is "good enough"? International Journal on Universal Access in the Information Society, Springer, 16(3), 713-723 (2017). doi: 10.1007/s10209-016-0498-4

24. Hwang, F., Keates, S., Langdon, P.M., Clarkson P.J.: Movement time for motion-impaired users assisted by force-feedback: effects of movement amplitude, target width, and gravity well width. International Journal on Universal Access in the Information Society, Springer, 4(2), 85-95 (2005). doi: 10.1007/s10209-005-0114-5

25. Hwang, F., Keates, S., Langdon, P., Clarkson, P.J.: A haptic toolbar for motion-impaired users. Proceedings of the 3rd International Conference on Universal Access in HumanComputer Interaction / 11th International Conference on Human Computer Interaction, Springer (2005).

26. Carmichael, A., Rice, M., Sloan, D., Gregor, P.: Digital switchover or digital divide: A prognosis for usable and accessible interactive digital television in the UK. International Journal on Universal Access in the Information Society, 4(4), 400-416 (2006). doi:400416. 10.1007/s10209-005-0004-x

27. Keates, S., Clarkson, P.J.: Assessing the accessibility of digital television set-top boxes. Design for a more inclusive world (Keates, S., Clarkson, P.J., Langdon, P.M., Robinson, P. eds), Springer-Verlag, pp. 183-192. (2004).

28. Keates, S., Adams, R., Bodine, C., Czaja, S., Gordon, W., Gregor, P., Hacker, E., Hanson, V., Kemp, J., Laff, M., Lewis, C., Pieper, M., Richards, J., Rose, D., Savidis, A., Schultz, G., Snayd, P., Trewin, S., Varker, P.: (2007) Cognitive and learning difficulties and how they affect access to IT systems. International Journal on Universal Access in the Information Society, Springer, 5(4), 329-339 (2007). doi: 10.1007/s10209-006-0058-4

29. Keates, S.: A pedagogical example of teaching Universal Access. International Journal on Universal Access in the Information Society (UAIS), Springer, 14 (1), 97-110 (2015). doi: 10.1007/s10209-014-0398-4

30. Keates, S., Kyberd, P.J.: Robotic assistants for universal access. In: Universal Access in Human-Computer Interaction. Human and Technological Environments. Proceedings of UAHCI 2017. (eds. Antona, M., Stephanidis, C.) LNCS vol. 10279, Springer, pp. 527-538 (2017). doi: 10.1007/978-3-319-58700-4 43

31. Cooper, A: The inmates are running the asylum. SAMS Publishing, Indianapolis (1999). 
32. Keates, S., Lebbon, C., Clarkson, P.J.: Investigating industry attitudes to Universal Design. In: Proceedings of RESNA 2000, Orlando, FL. RESNAPress, pp. 276-278 (2000).

33. Buhler, C.: Robotics for rehabilitation - A European(?) perspective. Proceedings of the 5th International Conference on Rehabilitation Robotics (ICORR '97), Bath, UK, pp. 5-11 (1997).

34. Mahoney, R.: Robotic products for rehabilitation: Status and strategy. Proceedings of the 5th International Conference on Rehabilitation Robotics (ICORR '97), Bath, UK, pp. 1217 (1997).

35. Topping, M.J., Smith, J.K.: The development of handy 1. A robotic system to assist the severely disabled. Technology and Disability. Jan 10(2), 95-105. (1999).

36. Tijsma, H.A., Liefhebber, F., Herder, J.L.: Evaluation of new user interface features for the Manus robot arm. $9^{\text {th }}$ International Conference on Rehabilitation Robotics (ICORR 2005), pp. 258-263. IEEE (2005). doi:10.1109/ICORR.2005.1501097

37. Keates, S., Clarkson, P.J., Robinson, P.: Developing a practical inclusive interface design approach. Interacting with Computers. 14(4), 271-299 (2002). doi:10.1016/S09535438(01)00054-6

38. Keates, S., Clarkson, P.J., Robinson, P.: Design for participation: providing access to einformation for older adults. International Journal on Universal Access in the Information Society (UAIS), Springer, 3(2), 149-163 (2004). doi: 10.1007/s10209-004-0093-y

39. Grundy, E., Ahlburg, D., Ali, M., Breeze, E., Sloggett, A.: Disability in Great Britain. Department of Social Security, Research Report No. 94, Corporate Document Services, London, UK (1999).

40. Clarkson, P.J., Keates, S., Dong, H.: Quantifying design exclusion. Inclusive design: design for the whole population, Springer-Verlag, London (Clarkson, P.J., Coleman, R., Keates, S., Lebbon, C.), pp. $422-437$ (2003).

41. The Inclusive Design Toolkit. Available at: http://www.inclusivedesigntoolkit.com/ (Last accessed 29/01/18).

42. Keates, S.: Pragmatic research issues confronting HCI practitioners when designing for universal access. International Journal on Universal Access in the Information Society (UAIS), Springer, 5(3), 269-278 (2006). doi: 10.1007/s10209-006-0050-z 